Bài báo khoa học

\title{
Sử dụng dữ liệu MODIS đa thời gian đánh giá biến động khô hạn tại Tây Nguyên giai đoạn 2001-2020
}

\author{
Trần Văn Thương ${ }^{1 *}$, Cao Thanh Xuân ${ }^{1}$, Nguyễn Trọng Hiệu ${ }^{2}$, Phan Văn Tuấn ${ }^{3}$, Danh $M^{\prime}{ }^{4}{ }^{4}$ \\ ${ }^{1}$ Trường Đại học Thủ Dầu Một, Bình Dương; thuong.tran@tdmu.edu.vn; xuanct@tdmu.edu.vn; \\ ${ }^{2}$ Trung tâm Khoa học Công nghệ Khí tượng Thủy văn và Môi trường; hieu.nt38@gmail.com; \\ ${ }^{3}$ Trường Đại học Lâm Nghiệp - phân hiệu Đồng Nai; phanvantuandc@gmail.com; \\ ${ }^{4}$ Viện Địa lý Tài nguyên Thành phố Hồ Chí Minh, VAST; dmon@hcmig.vast.vn \\ *Tác giả liên hệ: thuong.tran@tdmu.edu.vn; Tel.: +84-938603357
}

Ban Biên tập nhận bài: 12/9/2021; Ngày phản biện xong: 4/10/2021; Ngày đăng bài: $25 / 1 / 2022$

Tóm tắt: Mục tiêu của nghiên cứu này nhằm sử dụng chỉ số chuẩn hóa sức khỏe thực vật (Standardized Vegetation Health Index-SVHI) để đánh giá biến động hạn nông nghiệp năm tại khu vực Tây Nguyên. Dữ liệu MODIS đa thời gian giai đoạn 2001-2020 đã được sử dụng để tính toán nhiệt độ bề mặt và chỉ số chuẩn hóa khác biệt thực vật, hai thông số đầu vào của chỉ số khô hạn đã áp dụng. Bên cạnh đó, chỉ số chuẩn hóa lượng mưa (SPI) tại 5 trạm khí tượng cũng được tính toán để đánh giá độ tin cậy của chỉ số SVHI. Đồng thời, tiếp cận hồi quy không gian đã được áp dụng để đánh giá biến động khô hạn năm tại lãnh thổ nghiên cứu theo không gian và thời gian. Kết quả nghiên cứu chỉ ra rằng hệ số tương quan giữa $\mathrm{SVHI}$ và $\mathrm{SPI}$ tại 5 trạm quan trắc đều trên mức trung bình tại độ tin cậy $95 \%(\mathrm{r}>0,5, \mathrm{p}<0,05)$. Ngoài ra, cấp độ khô hạn cực đoan đã xảy ra tại lãnh thổ nghiên cứu vào năm 2005 và 2016 , đồng nhất với năm diễn ra El Niño. Hơn nữa, diễn biến của khô hạn có xu thế tăng tại đất nông nghiệp, trong khi, xu thế giảm được phát hiện tại đất rừng tại tất cả các tỉnh. Kết quả từ nghiên cứu này gớp phần cung cấp tài liệu tham khảo hữu ích cho nhà quản lý trong việc đề xuất các chiến lược giảm thiểu rủi ro hạn hán và bảo vệ rừng.

Từ khóa: SVHI; VHI; VCI; TCI; MODIS; Bình phương tối thiểu.

\section{1. Đặt vấn đề}

Trong những thập kỷ gần đây, hạn hán đã gây nhiều thiệt hại về kinh tế, ảnh hưởng đến đời sống con người và môi trường sinh thái của 130 quốc gia trên thế giới [1-2]. Tác động của hạn hán đã gây thiệt hại ít nhất 124 tỷ USD về kinh tế và ảnh hưởng tới hơn 1,5 tỷ người trên toàn thế giới từ năm 1998 đến năm 2017 [3]. Theo báo cáo của Liên hợp quốc năm 2021, nạn khan hiếm nước và hạn hán dự báo sẽ gây thiệt hại với quy mô tương đương với đại dịch COVID-19 với các rủi ro đang tăng nhanh do sự ấm lên toàn cầu [4]. Trong lĩnh vực nông nghiệp, trồng trọt và chăn nuôi là những ngành bị ảnh hưởng nặng nề nhất do thiên tai liên quan đến bên đồi khí hậu và trong số đó, gần $86 \%$ hậu quả liên quan đến vấn đề khô hạn [3]. Tại Việt Nam, hạn hán là một loại thiên tai phổ biến, đứng thứ 3 sau bão và lũ [5]. Hạn hán ảnh hưởng đến đời sống xã hội và gây nhiều thiệt hại về dân sinh, kinh tế và môi trường. Những năm qua, Nhà nước đã ưu tiên thực hiện nhiều giải pháp ứng phó hạn hán nhờ đó đã giảm thiểu được thiệt hại do hạn hán gây ra [6]. Tuy nhiên, tình trạng hạn hán diễn biến ngày càng phức tạp, đặc biệt, bởi tác động biến đổi khí hậu, tình trạng hạn hán sẽ diễn ra ngày càng gay gắt hơn [7]. Do đó, nghiên cứu khô hạn không chỉ là vấn đề được quan tâm ở từng quốc gia, khu vực, và vùng lãnh thổ, mà còn ở cấp độ toàn cầu. 
Chỉ số khô hạn như là một công cụ hiệu quả để phản ánh thực trạng hạn tại một lãnh thổ cụ thể [8]. Trong quá trình nhận định các loại hạn, việc tính toán chỉ số khô hạn được ưu tiên hàng đầu vì những ảnh hưởng của loại hạn này lên loại hạn khác đã gây khó khăn cho việc nhận định chính xác các loại hạn theo cách thông thường [9-10]. Trong nhiều năm qua, hàng loạt các chỉ số khô hạn đã được thiết lập để đánh giá biến động hạn trên quy mô toàn cầu và cấp độ địa phương [11]. Năm 2016, Tổ chức khí tượng thế giới công bố sổ tay chỉ số khô hạn với 42 chỉ số dựa trên một số thông số đầu vào của mô hình như: khí tượng (23 chỉ số); độ ẩm đất (4 chỉ số); viễn thám (10 chỉ số); tổng hợp (5 chỉ số) [12]. Tuy nhiên, kinh nghiệm trên thế giới cho thấy hầu như không có một chỉ số nào có ưu điểm vượt trội so với các chỉ số khác tại một vùng địa lý nào đó [12-13] do sự khác biệt về điều kiện tự nhiên của từng địa phương. Chẳng hạn, chỉ số Palmer (PDSI) đã và đang được Bộ nông nghiệp Mỹ sử dụng rộng rãi để xác định sự cần thiết và mức hỗ trợ khẩn cấp cho các vùng chịu tác động của hạn hán, tuy nhiên chỉ số này cũng chỉ phù hợp tốt với các vùng có diện tích rộng lớn với điều kiện địa hình, địa mạo đồng nhất [14]. Ở các bang miền Tây nước Mỹ, với địa hình núi non và đặc điểm tiếu khí hậu cục bộ phức tạp, phải sử dụng thêm một số chỉ số khô hạn khác, ví dụ như chỉ số cấp nước bề mặt (SWSI) để hỗ trợ $[12,14]$. Do đó, việc lựa chọn chỉ số thích hợp đóng vai trò quan trọng trong việc đánh giá nguy cơ hạn ở cấp độ địa phương.

Nhiều nghiên cứu về khô hạn trên thế giới đã sử dụng đa dạng nguồn ảnh vệ tinh được thu nhận từ các bộ cảm biến khác nhau như Advanced Very High Resolution Radiometer (AVHRR) [15], Moderate Resolution Imaging Spectroradiometer (MODIS) [14, 16], Landsat [17-18], hoặc Sentinel [19]. Trong số đó, ảnh vệ tinh MODIS phóng năm 1999 (Terra) và 2002 (Aqua) đã được sử dụng rất phổ biến cho các nghiên cứu về khô hạn vì có độ phân giải thời gian lớn (2 ảnh/ngày), độ phân giải bức xạ cao (12bit), số lượng kênh phổ lớn (36 kênh) [20-21], và độ phân giải không gian đa dạng từ $250 \mathrm{~m}$ đến $1 \mathrm{~km}$. Bên cạnh đó, ở những vùng nhiệt đới, độ che phủ từ các đám mây đã tạo nên một thách thức lớn cho các cảm biển quang phổ trong quá trình thu nhận ảnh nhưng với chu kì lặp cao (1 ngày), các giá trị trung bình của MODIS đã giảm thiểu được tác động này $[18,22]$. Trong hai thập kỉ qua, hàng loạt các chỉ số khô hạn phổ biến được phát triển từ dữ liệu vệ tinh MODIS [10] bao gồm chỉ số bốc thoát hơi (ET/PET) [23], chỉ số chuẩn hóa thực vật (SVI) [24-25], hoặc chỉ số chuẩn hóa khác biệt nhiệt độ (NDTI) [26]. Hầu hết các chỉ số này đều sử dụng các thông số đơn để đánh giá khô hạn mà bỏ qua việc kết hợp giữa các thông số khác đế phản ánh toàn diện các đặc điểm lớp phủ bề mặt của một địa phương. Trong khi, nhiều nghiên cứu đã chứng minh rằng việc đề xuất hoặc đánh giá biến động hạn hán nên được dựa trên các chỉ số tổng hợp và có nhiều thông số đầu vào, để phản ánh toàn diện các đặc trưng về khô hạn [13]. Do đó, một chỉ số tổng hợp từ ảnh vệ tinh MODIS, từ việc kế thừa những ưu điểm và nhằm cải thiện những khuyết điểm của các chỉ số trước, đã được áp dụng để đánh giá biến động hạn nông nghiệp tại khu vực nghiên cứu.

Tây Nguyên được nhận định là vùng trọng điểm cây cà phê của Việt Nam (chiếm $85 \%$ diện tích và $90 \%$ sản lượng) và được đánh giá như "lá phổi xanh" của quốc gia với tổng diện tích có rừng gần 2,6 triệu ha, chiếm $17,5 \%$ diện tích có rừng cả nước năm 2019 [27]. Tuy nhiên, độ che phủ rừng đã giảm đáng kể (hơn 20\%) giai đoạn 1990-2019, từ 60\% xuống dưới 40\% [28-29]. Sự giảm thiểu lớp phủ thực vật đã dẫn đến sự gia tăng dòng chảy tràn trên bề mặt, hạn chế quá trình thẩm thấu nước mưa, làm giảm thiểu lượng nước ngầm được tích trữ để cung ứng nước tưới cho cây trồng [28]. Do đó, vào mùa khô, hạn hán diễn ra nghiêm trọng, gây ảnh hưởng nặng nề lên cây lâu năm (chủ yếu là cây cà phê) và một phần nhỏ diện tích lúa và hoa màu. Vì vậy, tầm quan trọng của việc theo dõi khô hạn ở khu vực Tây Nguyên đã được khẳng định tại một vài nghiên cứu [5,30,31]. Các nghiên cứu trước đây đã sử dụng các chỉ số đơn biến để đánh giá hạn khí tượng và phân vùng khô hạn [31-33]. Những nghiên cứu gần đây nhất [11,33] đã thiết lập chỉ số chuẩn hóa khác biệt khô hạn (Normal Different Drought Index-NDDI) từ việc kết hợp giữa chỉ số chuẩn hóa 
khác biệt thực vật (NDVI) và chỉ số chuẩn hóa khác biệt nước (NDWI), thu nhận từ ảnh vệ tinh Landsat, để đánh giá hạn tháng 3, giai đoạn 1989-2017. Trên thực tế, khô hạn được ưu tiên đánh giá theo mùa (ví dụ: 3,6,12,24 tháng) hơn là sử dụng dữ liệu 1 tháng duy nhất nhằm giảm thiểu khả năng ảnh hưởng của các yếu tố tác động [34-35]. Bên cạnh đó, chu kì lặp của ảnh vệ tinh Landsat là 16 ngày, người dùng chỉ thu nhận được nhiều nhất 2 cảnh/tháng, nên dung lượng mẫu này không phản ảnh một cách đầy đủ thực trạng khô hạn cho toàn vùng. Thêm vào đó, việc áp dụng thành công hay không thành công một chỉ số hạn nào đó còn phụ thuộc vào cơ sở dữ liệu quan trắc sẵn có [36]. Vì vậy, việc phát triển và áp dụng một chỉ số khô hạn tổng hợp phù hợp sẽ có ý nghĩa thực tiễn đối với việc đánh giá, xác định khả năng hạn hán và đề ra giải pháp ứng phó thiên tai cho khu vực Tây Nguyên.

\section{Dữ liệu và Phương pháp nghiên cứu}

\subsection{Tổng quan lãnh thổ nghiên cưu}

Tây Nguyên $\left(107^{\circ} 12\right.$ - 108 59'37” kinh độ Đông $11^{0} 12^{\prime} 00^{\prime}$ - $15^{0} 27^{\prime} 15^{\prime}$ "vĩ độ Bắc) với diện tích $54.641 \mathrm{~km}^{2}$, chiếm $1 / 6$ diện tích của cả nước, là một trong bảy vùng nông nghiệp của Việt Nam (Hình 1). Tây Nguyên là vùng cao nguyên có tính phân bậc độ cao rõ rệt (500-1.000-1.500 m), được bao bọc về phía Đông bởi những dãy núi và khối núi cao (chính là Trường Sơn Nam). Đặc điểm khí hậu Tây Nguyên thuộc vùng khí hậu nhiệt đới, gió mùa, ẩm, mang tính chất cận xích đạo với hai mùa rõ rệt. Mùa khô bắt đầu từ tháng XI và kết thúc vào tháng IV năm sau, với đặc tính nóng, thiếu nước trầm trọng; mùa mưa bắt đầu từ tháng $\mathrm{V}$ và kết thúc vào tuần cuối tháng $\mathrm{X}, 90 \%$ lượng mưa năm tập trung vào mùa mưa. Nhiệt độ trung bình năm khoảng $20^{\circ} \mathrm{C}$, điều hoà quanh năm, biên độ nhiệt ngày và đêm chênh lệch cao $\left(>5,5^{\circ} \mathrm{C}\right)$.

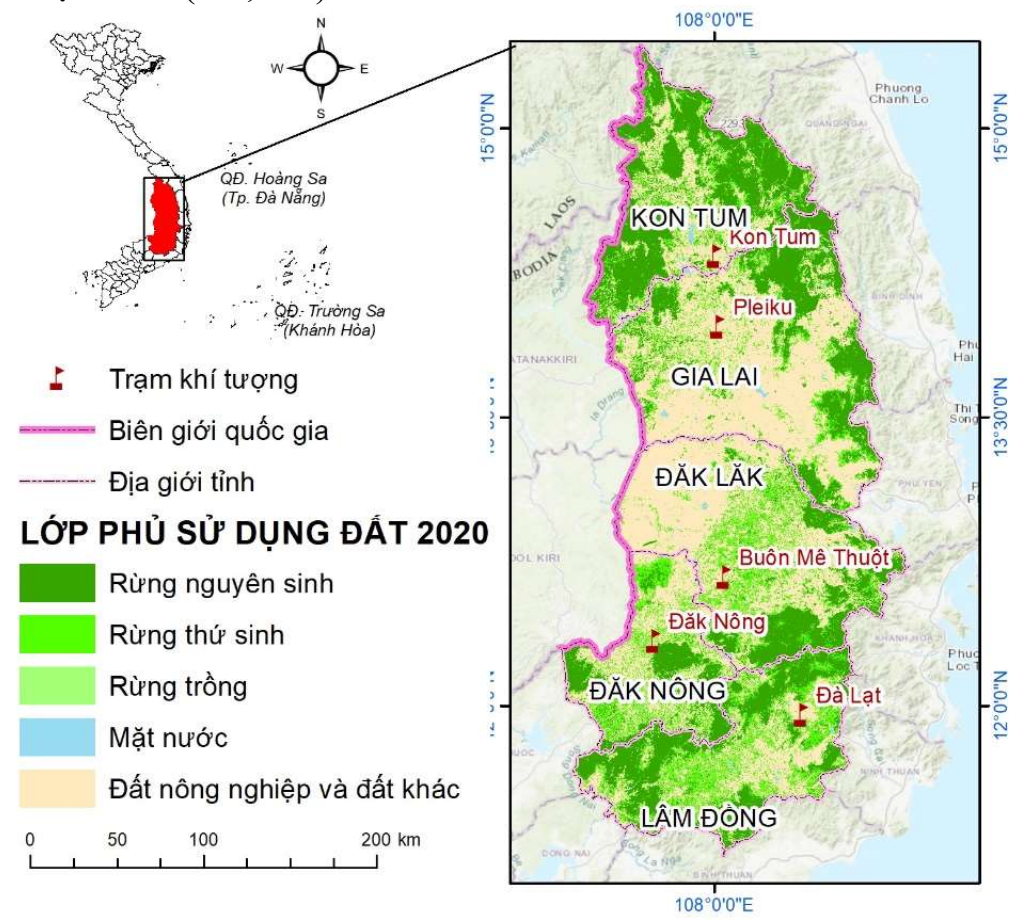

Hình 1. Vị trí lãnh thổ nghiên cứu.

\subsection{Dũ liệu nghiên cưu}

Trong nghiên cứu này, dữ liệu quan sát Trái Đất từ các sản phẩm của ảnh vệ tinh MODIS, chu kì lặp 1 ngày, giai đoạn 2001-2020 đã được sử dụng (Bảng 1). Nguồn ảnh được lấy từ Land Processes Distributed Active Archive Center (LPDAAC) cho cả hai cảm 
biến Terra (buổi sáng) và Aqua (buổi chiều). Thời gian thu nhận ảnh của hai cảm biến tại khu vực nghiên cứu dao động từ 10 giờ 30 phút đến 11 giờ 30 phút sáng cho đầu thu Terra và từ 13 giờ 30 phút đến 14 giờ 30 phút chiều cho cảm biến Aqua [37]. Tất cả các cảnh ảnh đều được xử lý trên nền tảng điện toán đám mây Google Earth Engine (https://earthengine.google.com/). Sau đó, các giá trị trung bình năm, giá trị lớn nhất, và giá trị nhỏ nhất cho các chỉ số quang phổ (LST và NDVI) tương ứng cho giai đoạn 2001 2020 đã được thu nhận tại độ phân giải không gian 1 km.

Bảng 1. Dũ̃ liệu MODIS được sử dụng trong nghiên cứu.

\begin{tabular}{ccccc}
\hline Dữ liệu & Mô tả & Sản phẩm & $\begin{array}{c}\text { Độ phân giải } \\
\text { không gian }\end{array}$ & $\begin{array}{c}\text { Độ phân giải } \\
\text { thời gian }\end{array}$ \\
\hline LST & Nhiệt độ bề mặt & $\begin{array}{c}\text { MOD11A1 } \\
\text { MYD11A1 }\end{array}$ & $1000 \mathrm{~m}$ & 1 ngày \\
\multirow{2}{*}{ NDVI } & Chỉ số chuẩn khóa khác biệt & $\begin{array}{c}\text { MOD09GA } \\
\text { thực vật }\end{array}$ & $\begin{array}{c}1000 \mathrm{~m} \\
\text { MYD09GA }\end{array}$ & 1 ngày \\
\hline
\end{tabular}

Các giá trị LST MOD11A1 và MYD11A1 được truy xuất bằng thuật toán cửa sổ phân tách trong điều kiện bầu trời quang đãng (với độ tin cậy trên $95 \%$ tại độ cao địa hình $\leq$ $2000 \mathrm{~m}$ hoặc $\geq 66 \%$ tại độ cao địa hình $>2000 \mathrm{~m}$ và trên hồ) [38]. Chi tiết tham khảo tại: https://pdaac.usgs.gov/products/mod11a1v006/. Đồng thời, giá trị bức xạ của kênh đỏ $(\mathrm{R})$ và cận đỏ (NIR) từ các sản phẩm MOD09GA và MYD09GA đã được sử dụng để tính toán chỉ số NDVI [39], theo công thức (1):

$$
N D V I=\frac{N I R-R}{N I R+R}
$$

Bên cạnh đó, dữ liệu khí tượng tại 5 trạm khí tượng của khu vực Tây Nguyên cũng được sử dụng để tính toán các chỉ số chuẩn hóa lượng mưa (SPI) nhằm đánh giá độ tin cậy của chỉ số khô hạn từ vệ tinh. Dữ liệu này được tổng hợp từ Niên giám thống kê giai đoạn 2001-2020 của các tỉnh thuộc khu vực Tây Nguyên tại các trạm Pleiku, Kon Tum, Buôn Mê Thuột, Đăk Nông, và Đà Lạt (Hình 1).

\subsection{Chỉ số khô hạn}

Trong nghiên cứu này, chỉ số chuẩn hóa sức khỏe thực vật đã được phát triển ở dạng biến ngẫu nhiên có phân phối chuẩn $\mathrm{Z} \sim \mathrm{N}(0,1)$ được biến đổi từ xác suất tích lũy, dựa theo chỉ số chuẩn hóa lượng mưa (SPI) của McKee (1993) [40], theo công thức (2):

$$
S V H I=\frac{V H I_{i}-\overline{V H I}}{\sigma_{V H I}}
$$

Trong đó VHI là chỉ số sức khỏe thực vật (Vegetation Health Index); $\overline{V H I}$ và $\sigma_{V H I}$ lần lượt là giá trị trung bình và độ lệch chuẩn của VHI trong giai đoạn nghiên cứu.

Chỉ số sức khỏe thực vật (VHI) lần đầu tiên được đề xuất bởi Kogan (1995) [7] để nhận định hạn nông nghiệp tại lãnh thổ Hoa Kỳ, trên cơ sở tổng hợp chỉ số điều kiện nhiệt độ (Temperature Condition Index) và chỉ số điều kiện thực vật (Vegetation Condition Index) từ ảnh vệ tinh AVHRR với độ phân giải không gian $4 \mathrm{~km}$, theo công thức (3). Tuy nhiên, trong nghiên cứu này, với độ phân giải không gian $1 \mathrm{~km}$ của ảnh vệ tinh MODIS, kết quả nghiên cứu có thể phản ánh tốt hơn thực trạng khô hạn ở cấp độ vùng.

$$
V H I_{i}=\alpha * V C I_{i}+(1-\alpha) * T C I_{i}
$$

Trong đó, $V C I$ là chỉ số điều kiện thực vật; $T C I$ là chỉ số điều kiện nhiệt độ bề mặt; $i$ là năm tương ứng; $\alpha$ là trọng số khác biệt giữa $V C I$ và $T C I$, giá trị này phụ thuộc vào mối quan hệ giữa nhiệt độ và độ ẩm và được xác định dựa trên sự tương quan giữa NDVI và LST. 
Chỉ số VCI và chỉ số TCI lần lượt được tính toán theo công thức (4) và (5):

$$
\begin{aligned}
V C I_{i} & =\frac{V_{i, \text { mean }}-V_{\text {min }}}{V_{\text {max }}-V_{\text {min }}} \\
T C I_{i} & =\frac{T_{\text {max }}-T_{i, \text { mean }}}{T_{\text {max }}-T_{\text {min }}}
\end{aligned}
$$

Trong đó, $V_{\max }, V_{\min }$, và $T_{\max }, T_{\min }$ lần lượt là các giá trị lớn nhất và giá trị nhỏ nhất tương ứng của chỉ số thực vật và nhiệt độ bề mặt (LST) giai đoạn 2001-2020; $V_{\text {mean }}, T_{\text {mean }}$ là giá trị trung bình từng năm của NDVI và LST trong giai đoạn nghiên cứu; $i$ là năm tương ứng.

Mặc dù chỉ số VHI có nhiều ưu điểm trong việc đánh giá thực trạng hạn nông nghiệp, nhưng các giá trị trung bình theo thời gian được tính toán với ngưỡng giá trị từ 0 đển 100 sẽ có sai số và không có phân bố chuẩn xác suất [42-43]. Do đó, sự chuyển đổi từ giá trị thường sang giá trị chuẩn hóa của các thông số đầu vào nhằm tăng cường phân phối chuẩn và giảm thiểu độ lệch chuẩn của dữ liệu [44]. Đồng thời, quá trình chuẩn hóa dữ liệu của một chuỗi số liệu (biến độc lập) theo phân phối gamma (đó là tổng của một số biến độc lập theo phân phối mũ) sẽ góp phần giảm sai số tuyệt đối theo thời gian và tuân theo phân bố chuẩn trong quá trình đánh giá các biến động môi trường [44], cũng như tạo thuận lợi trong việc đánh giá độ tin cậy của dữ liệu với chỉ số chuẩn hóa lượng mưa SPI, công thức (5):

$$
S P I=\frac{P_{i}-\bar{P}}{\sigma_{P}}
$$

Trong đó, $P_{i}$ là lượng mưa năm thứ i; $\bar{P}$ là lượng mưa trung bình trong giai đoạn nghiên cứu; và $\sigma_{P}$ là độ lệch chuẩn của mưa năm.

Sự phân chia các cấp độ hạn của SPI và SVHI được trình bày trong Bảng 2 , tham khảo tại [40-41]. Giá trị của chỉ số SVHI thuộc tập hợp số thực và dao động từ $(-\infty,+\infty)$ cho các giá trị từ ẩm ướt đến khô hạn. Giá trị SVHI dưới 0 được xem là ngưỡng giới hạn của khô hạn, trong khi các khu vực có giá trị SVHI lớn hơn 0 được coi là ẩm ướt. Trong nghiên cứu này, các ngưỡng giá trị cho phân cấp độ ẩm của hai chỉ số SPI và SVHI đã được gộp lại nhằm giảm bớt sự gây nhiễu thông tin cho việc nhận định các cấp độ hạn tại khu vực nghiên cứu.

Bảng 2. Ngưỡng chỉ tiêu các cấp độ hạn theo SPI và SVHI tại Tây Nguyên.

\begin{tabular}{cccc}
\hline Cấp độ & SPI & SVHI & Mô tả \\
\hline D0 & SPI $>-1$ & SVHI $>0$ & Ầm ướt \\
D1 & $-1,5<\mathrm{SPI} \leq-1$ & $-1<\mathrm{SVHI} \leq 0$ & Hạn nhẹ \\
D2 & $-2<\mathrm{SPI} \leq-1,5$ & $-2<\mathrm{SVHI} \leq-1$ & Hạn vừa \\
$\mathrm{D} 3$ & $\mathrm{SPI} \leq-2$ & $\mathrm{SVHI} \leq-2$ & Hạn nặng và cực đoan \\
\hline
\end{tabular}

\subsection{Phân tích biến động}

Trong nghiên cứu này, hệ số góc $a$ phương trình xu thế $(\mathrm{y}=\mathrm{ax}+\mathrm{b})$, dựa trên phương pháp bình phương tối thiểu (OLS), đã được sử dụng để đánh giá biến động của các chỉ số khô hạn theo không gian và thời gian. Phương pháp bình phương tối thiểu (OLS) là một thuật toán được sử dụng để ước lượng mối tương quan giữa các biến khác nhau. Phương pháp này đã được sử dụng rộng rãi trong nhiều nghiên cứu về thống kê không gian-thời gian cho các vấn đề liên quan đển hạn, mặn $[36,45]$. Chuỗi dữ liệu của chỉ số SVHI từ ảnh MODIS giai đoạn 2001-2020 đã được đưa vào sử dụng như biển phụ thuộc và thời gian cho cả gian đoạn tính được xem là biến độc lập [45]. Công thức tính hệ số góc của phương trình xu thế được thể hiện tại phương trình (7): 


$$
a=\frac{n \sum_{i=1}^{n} S I_{i} \times Y_{i}-\sum_{i=1}^{n} S I_{i} \times \sum_{i=1}^{n} Y_{i}}{n \sum_{i=1}^{n} S I_{i}^{2}-\left(\sum_{i=1}^{n} S I_{i}\right)^{2}}
$$

Trong đó, $a$ thể hiện sự thay đổi của giá trị của các chỉ số; $n$ là thời đoạn tính từ 20012020 (20 năm); SI thể hiện giá trị của các chỉ số khô hạn SVHI như biến phụ thuộc, $Y i$ là số lượng năm tương ứng như biến độc lập, $i-t h$ là giá trị năm tương ứng của cả hai biến. Giá trị SVHI càng dần về $-\infty$ thì mức độ khô hạn sẽ càng trở nên nghiêm trọng. Vì vậy, SVHI và hệ số góc a là hai đại lượng tỉ lệ nghịch. Tức là giá trị $a$ tiến dần về 0 có nghĩa rằng không có biến động theo thời gian của biến; giá trị $a$ lớn hơn 0 phản ánh xu thế giảm mức độ hạn theo dựa vào chỉ số $\mathrm{SVHI}$, và giá trị $a$ nhỏ hơn 0 thể hiện xu thế gia tăng của khô hạn. Do đó, để cung cấp cái nhìn trực quan cho quá trình thể hiện xu thế khô hạn trên hình vẽ, giá trị $(-1)$ đã được nhân thêm vào kết quả cuối cùng của hệ số góc. Bên cạnh đó, giá trị $a$ trong phương trình xu thế được kiểm định ý nghĩa thống kê bằng t-test với giá trị $\mathrm{p}<$ 0,05 .

\section{Kết quả và Thảo luận}

\section{1. Độ tin cậy của chỉ số chuẩn hóa sức khỏe thực vật (SVHI)}

Phương trình (2)-(5) đã được sử dụng để tính chỉ số SVHI và đánh giá diễn biến khô hạn thông qua chỉ số này tại Tây Nguyên cho giai đoạn 2001-2020. Trong nghiên cứu này, hệ số $\alpha=0,7$ của phương trình (2) đã được xác định dựa trên quá trình phân tích tương quan giữa chỉ số chuẩn hóa khác biệt thực vật (NDVI) và nhiệt độ bề mặt (LST). Hệ số này tương tự với hệ số trong công thức nguyên thủy [41] đã tìm ra dựa trên mối liên hệ giữa NDVI và LST. Đồng thời, độ tin cậy của chỉ số SVHI tại Tây Nguyên được kiểm định thông qua việc đánh giá tương quan với chỉ số chuẩn hóa lượng mưa (SPI) - được tính toán từ số liệu của trạm khí tượng mặt đất, theo công thức (6), được thể hiện tại Hình 2 . Chỉ số SPI đã được áp dụng rộng rãi trong rất nhiều nghiên cứu về hạn khí tượng trên thế giới và được áp dụng tại lãnh thổ nghiên cứu vào năm 2019 [31] nhằm tìm hiểu đặc điểm và đánh giá hạn khí tượng tại Tây Nguyên. Tuy nhiên, nhiều nghiên cứu đã chỉ ra rằng sự phụ thuộc hoàn toàn vào số liệu mưa của chỉ số SPI có thể dẫn đến sự sai lệch về kết quả ước lượng khi dự báo khô hạn trong thời gian dài (trên 24 tháng) [46-48]. Bên cạnh đó, khi áp dụng chỉ số SPI ở các chuỗi thời gian ngắn $(1,2$, hoặc 3 tháng) cho các vùng có lượng mưa theo mùa thấp, có thể dẫn sự sai lệch về kết quả do sự chênh lớn giữa giá trị ẩm (SPI >0) và hạn $(\mathrm{SPI}<0)[14,49]$.

Trong công thức nguyên thủy, [41] đã sử dụng NDVI để phản ánh nhiệt độ không khí và lượng mưa tại một khu vực nhất định, còn LST phản ánh sự thiếu hụt nước qua quá trình bốc hơi bởi nhiệt độ cao cũng như thể hiện các thông tin về độ ẩm của đất. Bên cạnh đó, một số nghiên cứu $[36,50]$ đã chứng minh rằng sự phản ánh nhiệt độ không khí, lượng mưa và bốc hơi được thể hiện qua mối quan hệ rất chặt chẽ giữa chỉ số thực vật và nhiệt độ bề mặt. Đồng thời, một vài nghiên cứu chỉ ra rằng nhiệt độ bề mặt là một trong những nhân tố chính tham gia vào các quá trình vật lý của bề mặt đất như cân bằng nước, năng lượng và $\mathrm{CO}_{2}[5]$. Bên cạnh đó, trong nghiên cứu này, quá trình chuẩn hóa dữ liệu đã không làm mất đi bản chất vật lý của các thông số đầu vào cho mô hình [51-52]. Vì vậy, SVHI có thể cung cấp những thông tin hữu ích cho quá trình giám sát hạn nông nghiệp tại một địa phương bởi sự phản ánh được khả năng thiếu hụt hay dư thừa nước của nó trong quá trình sản xuất nông nghiệp.

Kết quả đã thể hiện mối tương quan từ mức trung bình đến rất chặt giữa 2 chỉ số khô hạn (SPI và SVHI) $(\mathrm{r}>0,5)$ tại 5 trạm khí tượng với mức ý nghĩa thống kê $95 \%(\mathrm{p}<0,05)$ (Hình 2). Trên thực tế, mặc dù nhiều chỉ số khô hạn đã được phát triển trên thế giới, nhưng 
không phải chỉ số nào cũng có thể áp dụng cho tất các các vùng [12]. Đặc biệt, do lãnh thổ Việt Nam trải dài trên nhiều vĩ độ nên có sự khác biệt về điều kiện khí hậu (phân hóa Bắc Nam), địa hình và các yếu tố cũng có sự phân hóa theo vùng, miền. Hầu hết các chỉ số khô hạn nông nghiệp đã phát triển đều được xây dựng từ các thông số đơn lẻ hoặc so sánh sự khác biệt giữa lượng mưa và sự thoát hơi nước trong thời gian dài, về cơ bản không thể đại diện cho các sự thiếu nước trong một thời gian nhất định [53-54]. Bên cạnh đó, sự hạn chế về số lượng các trạm quan trắc cũng tạo nên một thách thức cho việc đánh giá khô hạn theo không gian ở cấp độ pixel. Hơn nữa, với địa hình cao nguyên tương đối bẳng phẳng và có tính phân bậc nên khí hậu sẽ có sự phân hóa theo độ cao. Điều này dẫn đến biến động hạn không chỉ phụ thuộc vào điều kiện lớp phủ sử dụng đất, mà còn phụ thuộc vào các yếu tố khí hậu [36]. Do đó, việc xác định chỉ số khô hạn phù hợp cho khu vực cần được dựa trên các tiếp cận đa biến và thông qua ứng dụng dữ liệu viễn thám và kỹ thuật địa không gian [44].
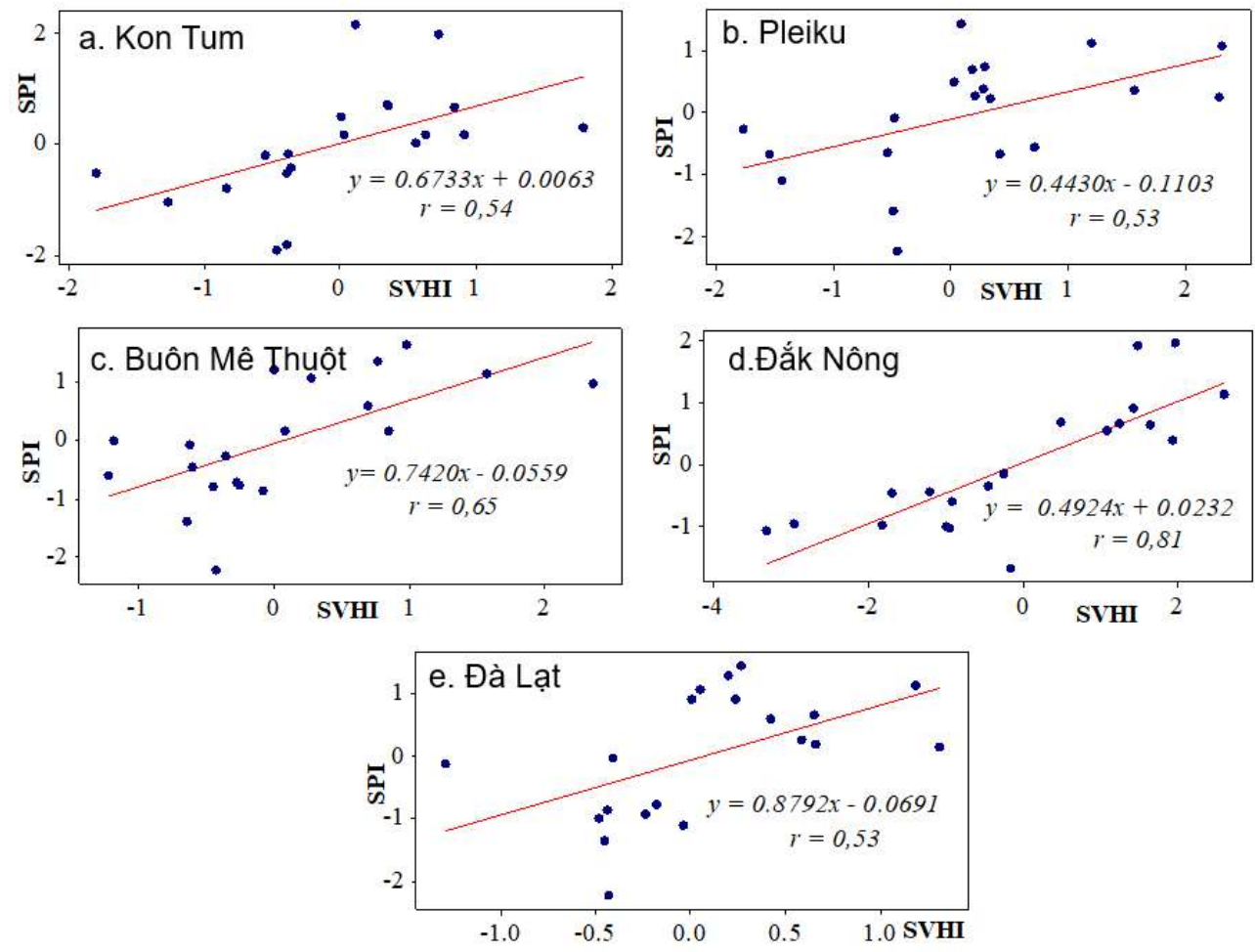

Hình 2. Mối quan hệ giữa SVHI và SPI tại các trạm khí tượng khu vực Tây Nguyên giai đoạn $2001-2020(\mathrm{p}<0,05)$.

\subsection{Diễn biến khô hạn tại Tây Nguyên giai đoạn 2001-2020}

Biến động các cấp độ hạn theo chỉ số chuẩn hóa sức khỏe thực vật được thể hiện tại Hình 3 và diện tích bị tác động phân theo các cấp độ hạn được thể hiện tại Hình 4 . Trên cơ sở diễn biến theo không gian và thời gian của chỉ số SVHI, hạn nặng và cực nặng ảnh hưởng nghiêm trọng nhất đến khu vực Tây Nguyên vào năm 2005 và 2016. Bên cạnh đó, cực đại của hạn nặng và cực đoan đã cách nhau 10 hoặc 11 năm (Hình 4). Những năm khô hạn ảnh hưởng nghiêm trọng và chu kì lặp của nó đều trùng với chu kì hoạt động của El Niño. Điều này cũng được phát hiện trong các nghiên cứu tương tự về khô hạn của $[11,31]$ tại khu vực này. Hơn nữa, nhiều năm qua, do nhiều diện tích rừng đã bị tàn phá nên việc giữ nước tự nhiên bị ảnh hưởng nghiêm trọng. Kể cả rừng đầu nguồn, hay là vùng lõi của một số cánh rừng cũng đã bị các đối tượng khai thác trái phép, nên trên thực tế độ che phủ của rừng suy giảm đáng kể. Bên cạnh đó, nước các dòng sông và dung tích trữ của các hồ 
chứa nước tại khu vực Tây Nguyên những năm qua đều ở mức thấp, kể cả trong mùa mưa. Do đó, tình hình khô hạn diễn ra ở khu vực này có xu hướng nghiêm trọng hơn, đặc biệt trong mùa khô [55-56].

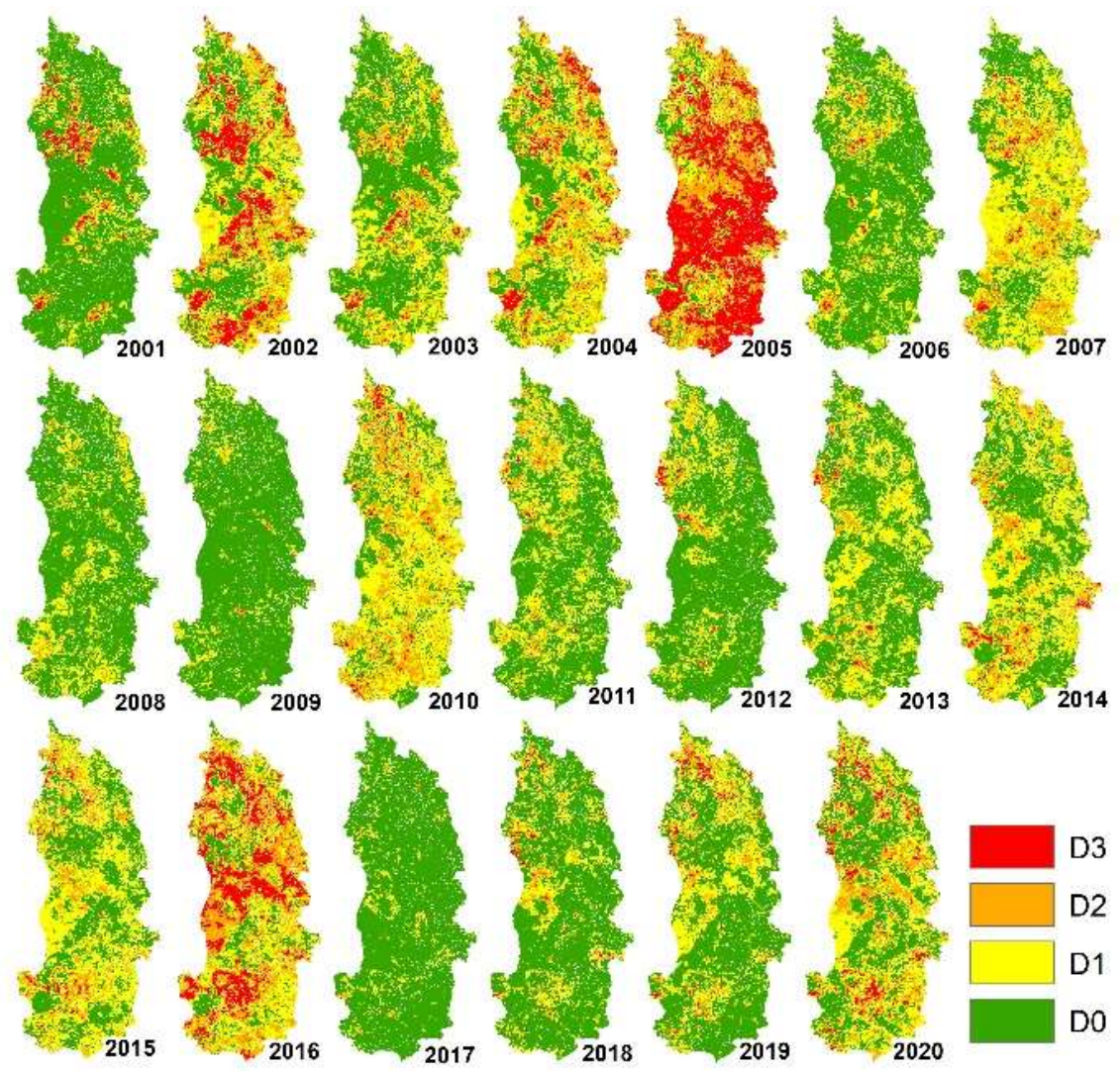

Hình 3. Biến động các cấp độ hạn theo chỉ số SVHI giai đoạn 2000-2020.

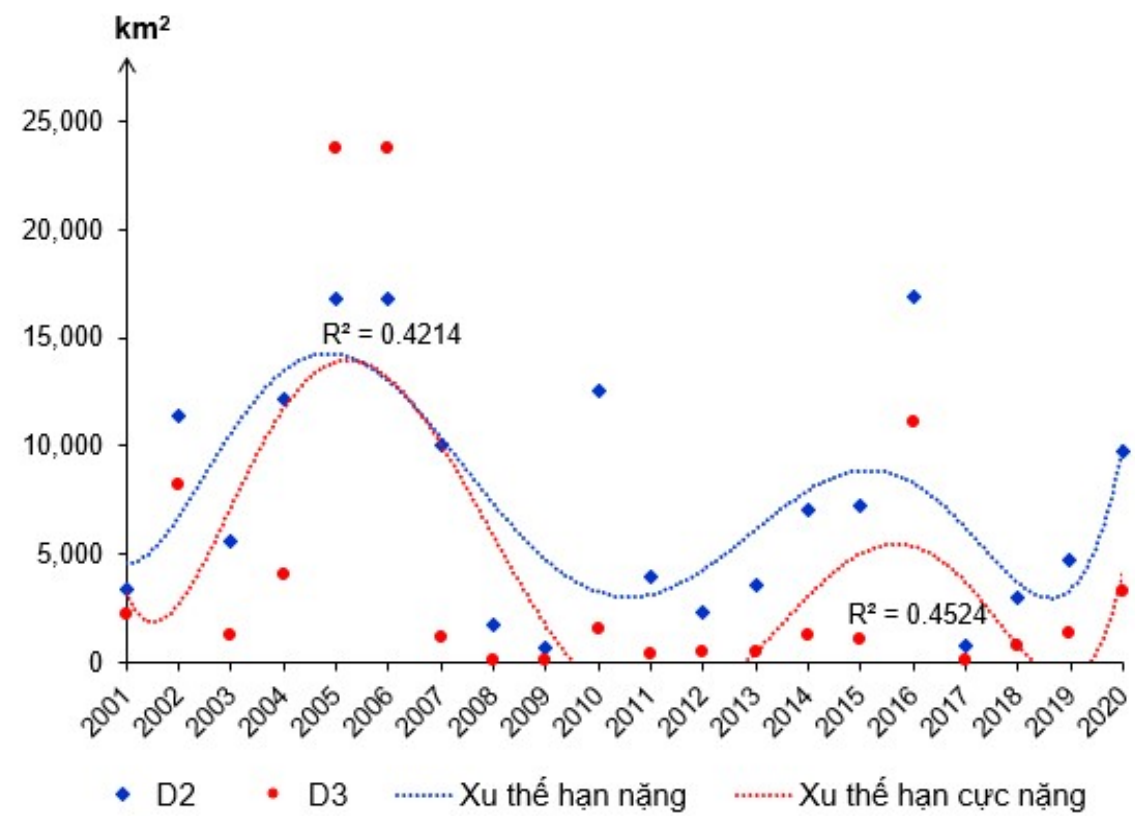

Hình 4. Diện tích bị ảnh hưởng bởi hạn nặng và cực đoan tại Tây Nguyên giai đoạn 2001-2020. 


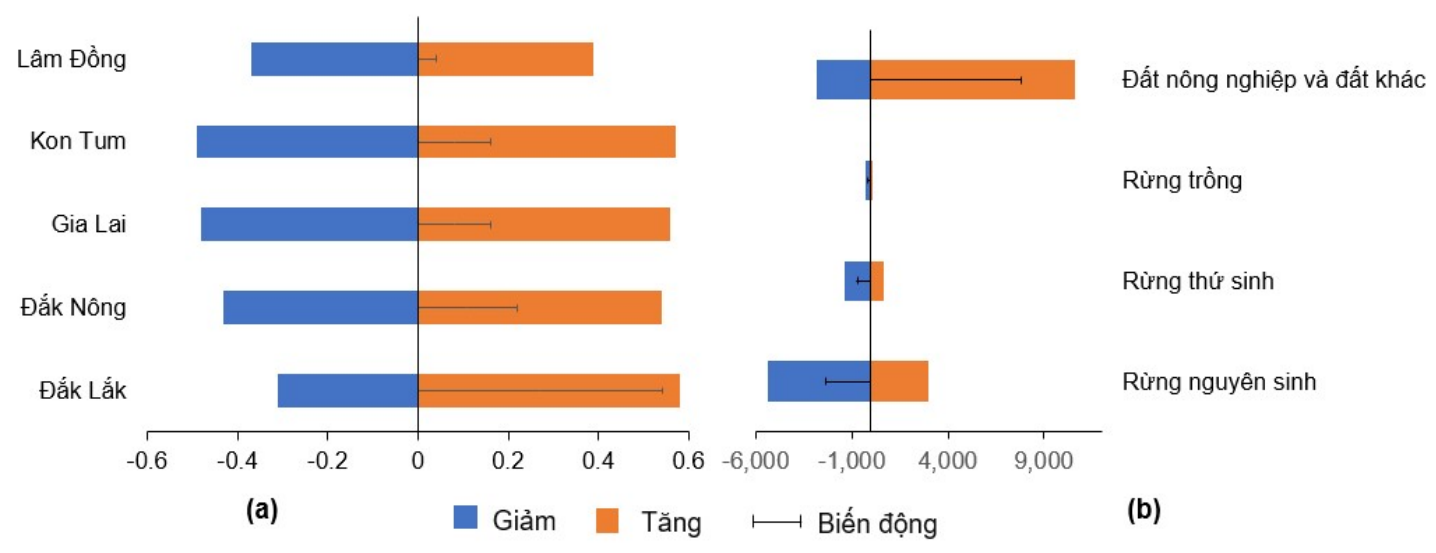

Hình 5. Xu thế biến động khô hạn phân theo tỉnh, thành phố (a) và theo lớp thực phủ (b).

Xu thế biến động của khô hạn dựa vào chỉ số SVHI phân theo tỉnh, thành phố và lớp phủ bề mặt được trình bày tại Hình 5 . Khô hạn có xu hướng tăng tại tất cả các tỉnh thuộc Tây Nguyên, điển hình tạo Đắk Lắk. Bên cạnh đó, những thay đổi của SVHI còn được đánh giá theo các loại lớp phủ sử dụng đất. Xu thế hạn gia tăng rõ rệt nhất xung quanh loại hình đất nông nghiệp và đất khác và có xu thế giảm tại các lớp phủ rừng. Đặc biệt, lớp phủ rừng nguyên sinh đóng vai trò rất quan trọng trong việc điều tiết tình hình hạn và làm giảm nguy cơ xảy ra khô hạn. Vì vậy, biến động các mức độ khô hạn ở Tây Nguyên chủ yếu xảy ra trên đất nông nghiệp. Đồng thời, biến động này có liên quan chặt chẽ đến tỉ lệ che phủ rừng.

\section{Kết luận}

Nghiên cứu đã tính toán và lập bản đồ biến đổi không gian của khô hạn dựa trên chỉ số chuẩn hóa sức khỏe thực vật (SVHI) sử dụng các sản phẩm của ảnh vệ tịnh MODIS ngày. Tiếp cận này đánh giá các cấp độ khô hạn trong khu vực nghiên cứu, rộng hơn là sử dụng nhiều hơn một tham số đầu vào. Hiệu quả của chỉ số đã được kiểm chứng thông qua đánh giá tương quan với chỉ số chuẩn hóa lượng mưa $\mathrm{SPI}(\mathrm{r}>0,5)$. Điều này góp phần xem xét rằng SVHI đóng vai trò quan trọng trong việc theo dõi các sự kiện khô hạn, so với các chỉ số khô hạn đã được áp dụng khác trong khu vực nghiên cứu. Kết quả phân tích cũng cho thấy hạn hán có xu thế gia tăng tại tất cả các tỉnh, tập trung chủ yếu ở lớp phủ đất nông nghiệp và các loại đất khác đất rừng.

Trong nghiên cứu này, phân tích chi tiết về các xu thế không gian của chỉ số khô hạn ở độ phân giải không gian $1 \mathrm{~km}$ đã chứng minh lợi thế của việc sử dụng SVHI trong đánh giá hạn hán. Việc sử dụng ảnh MODIS trong đánh giá xu thế hạn có ý nghĩa khoa học và áp dụng thực tiễn, khi phân bố trạm quan trắc mưa chưa đủ dày (5 trạm trên khu vực Tây Nguyên) và độ chính xác của số liệu mưa cũng là vấn đề còn nhiều tranh luận. Hơn nữa, việc thử nghiệm chỉ số SVHI để đánh giá các điều kiện khô hạn, dựa trên việc xác thực tại mỗi trạm khí tượng và các loại sử dụng đất, là khả dụng. Vì vậy, nghiên cứu này góp phần cung cấp tài liệu cho chính quyền địa phương trong công tác chuẩn bị các kế hoạch nhằm giảm thiểu tác động tiêu cực của khô hạn cho Tây Nguyên.

Mặc dù nghiên cứu đã chỉ ra những lợi thế của chỉ số SVHI trong đánh giá biến động không gian-thời gian của hạn nông nghiệp theo năm tại Tây Nguyên. Tuy nhiên, xu thế biến động hạn theo mùa $(1,3$, và 6 tháng) sẽ cung cấp tốt hơn các thông tin cho việc thành lập hệ thống cảnh báo hạn. Bên cạnh đó, việc đánh giá tương quan không gian giữa biến động hạn mùa, cơ cấu mùa vụ, và sự thay đổi sử dụng đất cần được thực hiện để đề xuất các giải pháp ứng phó với khô hạn. Do đó, những hạn chế của nghiên cứu này sẽ là bệ 
phóng cho các nghiên cứu trong tương laik hi áp dụng chỉ số SVHI để đánh giá khô hạn cho các khu vực có điều kiện địa lý tương tự.

Đóng góp của tác giả: Xây dựng ý tưởng nghiên cứu: T.V.T.; Lựa chọn phương pháp nghiên cứu: T.V.T., N.T.H.; Thu thập, phân tích, xử lý số liệu: C.T.X., P.V.T., D.M.; Viết bản thảo bài báo: T.V.T.; Chỉnh sửa bài báo: N.T.H.

Lời cảm ơn: Nghiên cứu này được tài trợ kinh phí bởi trường Đại học Thủ Dầu Một, trong khuôn khổ đề tài cấp Trường "Thiết lập công thức tính chỉ số khô hạn từ ảnh vệ tinh MODIS phục vụ đánh giá nguy cơ hạn hán tại Tây Nguyên”, mã số DT.21.02-063, theo quyết định số 787/QĐ-ĐHTDM, ban hành 13/05/2021.

Lời cam đoan: Tập thể tác giả cam đoan bài báo này là công trình nghiên cứu của tập thể tác giả, chưa được công bố ở đâu, không được sao chép từ những nghiên cứu trước đây; không có sự tranh chấp lợi ích trong nhóm tác giả.

\section{Tài liệu tham khảo}

1. Hiệu, L.T. Nghiên cứu đánh giá hạn hán vùng Đồng Bằng Sông Hồng, trường Đại học Khoa học Tự nhiên. Đại học Quốc gia Hà Nội: Hà Nội, 2012.

2. UNDRR, U.N.O. for D.R.R. GAR Special Report on Drought, 2021.

3. FAO. The Impact of Disasters and Crises on Agriculture and Food Security, 2021.

4. Minh Châu Liên Hợp Quốc. Sau COVID-19, hạn hán có thể sẽ là đại dịch kế tiếp, 2021.

5. Dinh, N.T.; Ha, N.T.T.; Thao, N.T.P.; Linh, N.T. 30 Years Monitoring Spatial Temporal Dynamics of Agricultural Drought in the Central Highlands Using Landsat Data. In Proceedings of the Geo-spatial Technologies and Earth Resources; Publishing House for Science and Technology: Hanoi City, Vietnam, 2017, 181-188.

6. Nam, H.N.; Hoc, Q.T. Những Vấn Đề Môi Trường Bức Xúc Do Hoạt Các Hoạt Động Phát Triển ở Tây Nguyên. In Proceedings of the Tuyển tập báo cáo khoa học Hội thảo khoa học quốc gia; Nhà xuất bản Đại học Quốc gia Hà Nội: Trung tâm Nghiên cứu Tài nguyên và Môi trường, Đại học Quốc gia Hà Nội, 2013.

7. MONRE Climate Change and Sea Level Rise Scenario for Vietnam. Ministry of Natural Resources and Environment (MORE), Hanoi, Viet Nam, 2016.

8. Tigkas, D.; Vangelis, H.; Tsakiris, G. DrinC: A Software for Drought Analysis Based on Drought Indices. Earth Sci. Inf. 2015, 8, 697-709. https://doi.org/ 10.1007/s12145-014-0178-y.

9. Hua, L.; Wang, H.; Sui, H.; Wardlow, B.; Hayes, M.J.; Wang, J. Mapping the Spatial-Temporal Dynamics of Vegetation Response Lag to Drought in a SemiArid Region. Remote Sen. 2019, 11, 1873.

10. Elhag, K.; Zhang, W. Monitoring and Assessment of Drought Focused on Its Impact on Sorghum Yield over Sudan by Using Meteorological Drought Indices for the Period 2001-2011. Remote Sen. 2018, 10, 1231.

11. Ha, N.T.T.; Nhuan, M.T.; Ngo-Thi, D.; Thao, N.T.P. Drought Disaster in the Central Highlands of Vietnam: Relationship Between Land-Use Change and Drought Impact. In Proceedings of the Proceedings of the $3^{\text {rd }}$ Global Summit of Research Institutes for Disaster Risk Reduction; Tatano, H., Collins, A., Eds.; Springer: Singapore 2021, 241-250. 
12. Svoboda, M.; Fuchs, B. Handbook of Drought Indicators and Indices, 2016.

13. Hao, Z.; Singh, V.P.; Xia, Y. Seasonal Drought Prediction: Advances, Challenges, and Future Prospects. Rev. Geophys. 2018, 56, 108-141. https://doi.org/ 10.1002/2016RG000549.

14. Mu, Q.; Zhao, M.; Kimball, J.S.; McDowell, N.G.; Running, S.W. A Remotely Sensed Global Terrestrial Drought Severity Index. Bull. Am. Meteorol. Soc. 2013, 94, 83-98.

15. Caccamo, G.; Chisholm, L.A.; Bradstock, R.A.; Puotinen, M.L. Assessing the Sensitivity of MODIS to Monitor Drought in High Biomass Ecosystems. Remote Sens. Environ. 2011, 115, 2626-2639.

16. Son, N.T.; Chen, C.F.; Chen, C.R.; Chang, L.Y.; Minh, V.Q. Monitoring Agricultural Drought in the Lower Mekong Basin Using MODIS NDVI and Land Surface Temperature Data. Int. J. Appl. Earth Obs. Geoinf. 2012, 18, 417-427.

17. Dlamini, T.; Songsom, V. Landsat-Based Drought Phenomenon Evaluation of Cassava and Sugar Cane in Northeast Thailand. J. Eng. Sci. Res. 2019, 3, 06-13.

18. Van Den Hoek, J.; Getirana, A.; Jung, H.C.; Okeowo, M.A.; Lee, H. Monitoring Reservoir Drought Dynamics with Landsat and Radar/Lidar Altimetry Time Series in Persistently Cloudy Eastern Brazil. Remote Sens. 2019, 11, 827. https://doi.org/ 10.3390/rs11070827.

19. Urban, M.; Berger, C.; Mudau, T.; Heckel, K.; Truckenbrodt, J.; Onyango Odipo, V.; Smit, I.; Schmullius, C. Surface Moisture and Vegetation Cover Analysis for Drought Monitoring in the Southern Kruger National Park Using Sentinel-1, Sentinel-2, and Landsat-8. Remote Sens. 2018, 10, 1482.

20. Beaton, A.; Whaley, R.; Corston, K.; Kenny, F. Identifying Historic River Ice Breakup Timing Using MODIS and Google Earth Engine in Support of Operational Flood Monitoring in Northern Ontario. Remote Sens. Environ. 2019, 224, 352-364.

21. Bajgain, R.; Xiao, X.; Basara, J.; Wagle, P.; Zhou, Y.; Zhang, Y.; Mahan, H. Assessing Agricultural Drought in Summer over Oklahoma Mesonet Sites Using the Water-Related Vegetation Index from MODIS. Int. J. Biometeorol. 2016, 61(2), 377-390.

22. Son, N.T.; Chen, C.F.; Chen, C.R.; Masferrer, M.G.M.; Recinos, L.E.M. Multitemporal Landsat-MODIS Fusion for Cropland Drought Monitoring in El Salvador. Geocarto Int. 2019, 34, 1363-1383. https://doi.org/10.1080/10106049.2018.1489421.

23. Mu, Q.; Zhao, M.; Running, S.W. Improvements to a MODIS Global Terrestrial Evapotranspiration Algorithm. Remote Sens. Environ. 2011, 115, 1781-1800.

24. Park, J.S.; Kim, K.T.; Choi, Y.S. Application of Vegetation Condition Index and Standardized Vegetation Index for Assessment of Spring Drought in South Korea. In Proceedings of the IGARSS 2008, 3, 774-777.

25. Peters, A.J.; Walter-Shea, E.A.; Ji, L.; Vina, A.; Hayes, M.; Svoboda, M.D. Drought Monitoring with NDVI-Based Standardized Vegetation Index. Photogramm. Eng. Remote Sens. 2002, 68, 71-75. 
26. McVicar, T.R.; Jupp, D.L. Using Covariates to Spatially Interpolate Moisture Availability in the Murray-Darling Basin: A Novel Use of Remotely Sensed Data. Remote Sens. Environ. 2002, 79, 199-212.

27. Triệu, V.; Phạm, T.; Đào, T. Kết Quả Thực Hiện Chiến Lược Phát Triển Lâm Nghiệp Việt Nam Giai Đoạn 2006-2020 và Đề Xuất Nội Dung Chiến Lược Phát Triển Lâm Nghiệp Việt Nam Giai Đoạn 2021-2030, Tầm Nhìn Đến Năm 2050; Tổ chức Nghiên cứu Lâm nghiệp Quốc tế (CIFOR): Bogor, Indonesia, Báo cáo chuyên đề 209, 2021. ISBN 978-602-387-144-5.

28. Trung Chuyên Giảm diện tích rừng ở Tây nguyên Available online: https://thanhnien.vn/thoi-su/giam-dien-tich-rung-o-tay-nguyen-1242144.html (accessed on 13 March 2021).

29. Bộ NN\&PTNN, B.N. nghiệp và P. triển N. thôn Quyết định số 1558/QĐ-BNNTCLN về công bố hiện trạng rừng năm 20202021.

30. Nguyen, Q.T.N.; Nguyen, L.D.; Nguyen, N.D.; Nguyen, T.; Bui, L.T.; Nguyen, L.K. Phân Vùng Hạn Hán Dựa Trên Chỉ Số Hạn và Mô Phỏng Chế Độ Thủy Văn Trên Lưu Vực Srepok Vùng Tây Nguyên. VNU J. Sci. Earth Environ. Sci. 2017, 33.

31. Vu, A.T.; Vu, T.H.; Trinh, H.D. The Characteristics and Trends of Meteorological Drought in Central Highlands. VN J. Hydrometeorol. 2019, 699, 50-58. https://doi.org/10.36335/VNJHM.2019(699).50-58.

32. Schults, T.J.R. Assessing the Relation between Groundwater Recharge and Drought Using Remote Sensing and Hydrological Modelling. Bachelor, Van Hall Larenstein: Netherlands, 2019.

33. Nguyen, H.T.T.; Mai, N.T.; Bui, C.D.; Nguyen, T.T.P. Mapping Droughts Over the Central Highland of Vietnam in El Niño Years Using Landsat Imageries. VNU J. Sci. Social Sci. Humanities 2016, 32, 255-263.

34. Hänsel, S.; Ustrnul, Z.; Łupikasza, E.; Skalak, P. Assessing Seasonal Drought Variations and Trends over Central Europe. Adv. Water Resour. 2019, 127, 53-75. https://doi.org/10.1016/j.advwatres.2019.03.005.

35. Svoboda, M.; Hayes, M.; Wood, D. Standardized Precipitation Index User Guide. World Meteorological Organization Geneva, Switzerland 2012, 900.

36. Tran, T.V.; Tran, D.X.; Myint, S.W.; Latorre-Carmona, P.; Ho, D.D.; Tran, P.H.; Dao, H.N. Assessing Spatiotemporal Drought Dynamics and Its Related Environmental Issues in the Mekong River Delta. Remote Sens. 2019, 11, 2742, https://doi.org/10.3390/rs11232742.

37. Justice, C.O.; Townshend, J.R.G.; Vermote, E.F.; Masuoka, E.; Wolfe, R.E.; Saleous, N.; Roy, D.P.; Morisette, J.T. An Overview of MODIS Land Data Processing and Product Status. Remote Sens. Environ. 2002, 83, 3-15.

38. Wan, Z. Collection-6 MODIS Land Surface Temperature Products Users' Guide. ICESS, University of California, Santa Barbara, 2013.

39. Didan, K. MOD13A1 MODIS/Terra Vegetation Indices 16-Day L3 Global 500m SIN Grid V006 [Data Set]. NASA EOSDIS LP DAAC 2015. https://doi.org/10.5067/MODIS/MOD13A1.006. 
40. McKee, T.B.; Doesken, N.J.; Kleist, J. The Relationship of Drought Frequency and Duration to Time Scales. In Proceedings of the Proceedings of the $8^{\text {th }}$ Conference on Applied Climatology; American Meteorological Society Boston, MA, 1993, 17, 179-183.

41. Kogan, F.N. Application of Vegetation Index and Brightness Temperature for Drought Detection. Adv. Space Res. 1995, 15, 91-100.

42. Aniruddha, B. Feature Scaling Standardization Vs Normalization. Anal. Vidhya 2020.

43. Shumway, R.H.; Stoffer, D.S. Characteristics of Time Series. In Time Series Analysis and Its Applications: With R Examples; Shumway, R.H., Stoffer, D.S., Eds.; Springer Texts in Statistics; Springer International Publishing: Cham, 2017, pp. 1-44. ISBN 978-3-319-52452-8.

44. Hao, Z.; Singh, V.P. Drought Characterization from a Multivariate Perspective: A Review. J. Hydrol. 2015, 527, 668-678.

45. Tran, T.V.; Tran, D.X.; Myint, S.W.; Huang, C.; Pham, H.V.; Luu, T.H.; Vo, T.M. Examining Spatiotemporal Salinity Dynamics in the Mekong River Delta Using Landsat Time Series Imagery and a Spatial Regression Approach. Sci. Total Environ. 2019, 687, 1087-1097.

46. Swain, S.; Patel, P.; Nandi, S. Application of SPI, EDI and PNPI Using MSWEP Precipitation Data over Marathwada, India. In Proceedings of the 2017 IEEE International geoscience and remote sensing symposium (IGARSS), IEEE, 2017, pp. 5505-5507.

47. Wu, H.; Hayes, M.J.; Wilhite, D.A.; Svoboda, M.D. The Effect of the Length of Record on the Standardized Precipitation Index Calculation. Int. J. Climatol. 2005, 25, 505-520. https://doi.org/10.1002/joc. 1142.

48. Mishra, A.K.; Singh, V.P. Drought Modeling - A Review. J. Hydrol. 2011, 403, 157-175. https://doi.org/10.1016/j.jhydrol.2011.03.049.

49. Das, P.K.; Dutta, D.; Sharma, J.R.; Dadhwal, V.K. Trends and Behaviour of Meteorological Drought (1901-2008) over Indian Region Using Standardized Precipitation-Evapotranspiration Index. Int. J. Climatol. 2016, 36, 909-916. https://doi.org/10.1002/joc.4392.

50. Amani, M.; Salehi, B.; Mahdavi, S.; Masjedi, A.; Dehnavi, S. TemperatureVegetation-Soil Moisture Dryness Index (TVMDI). Remote Sens. Environ. 2017, 197, 1-14.

51. Erhardt, T.M.; Czado, C. Standardized Drought Indices: A Novel Uni-and Multivariate Approach. arXiv preprint arXiv:1508.06476 2015.

52. de Carvalho Júnior, O.A.; Guimarães, R.F.; Silva, C.R.; Gomes, R.A.T. Standardized Time-Series and Interannual Phenological Deviation: New Techniques for Burned-Area Detection Using Long-Term MODIS-NBR Dataset. Remote Sens. 2015, 7, 6950-6985.

53. Cao, Y.; Chen, S.; Wang, L.; Zhu, B.; Lu, T.; Yu, Y. An Agricultural Drought Index for Assessing Droughts Using a Water Balance Method: A Case Study in Jilin Province, Northeast China. Remote Sens. 2019, 11, 1066. 
54. Vicente-Serrano, S.M.; Beguería, S.; Lorenzo-Lacruz, J.; Camarero, J.J.; LópezMoreno, J.I.; Azorin-Molina, C.; Revuelto, J.; Morán-Tejeda, E.; SanchezLorenzo, A. Performance of Drought Indices for Ecological, Agricultural, and Hydrological Applications. Earth Interact. 2012, 16, 1-27.

55. Tổng cục Khí tượng Thủy Văn Nước và Mùa Khô Tây Nguyên Available online: http://kttvqg.gov.vn/tin-tuc-tai-nguyen-nuoc-va-moi-truong-114/nuoc-va-muakho-tay-nguyen-5934.html (accessed on 13 July 2021).

56. Thông tin nông thôn Tây Nguyên Vài Nét Tổng Quan Available online: https://dantocmiennui.vn/tay-nguyen-vai-net-tong-quan/130717.html (accessed on 13 July 2021).

\title{
Examininging Drought Intensity in Central Highlands during the 2001-2020 period using Daily MODIS Time-Series Imagery
}

\author{
Tran Van Thuong ${ }^{*}$, Cao Thanh Xuan ${ }^{1}$, Nguyen Trong Hieu ${ }^{2}$, Phan Van Tuan ${ }^{3}$, Danh Mon ${ }^{4}$ \\ 1 Thu Dau Mot University, Binh Duong; thuong.tran@tdmu.edu.vn; xuanct@tdmu.edu.vn; \\ 2 Center for Hydro-Meteorological, Environmental Science and Technology; \\ hieu.nt38@gmail.com; \\ 3 Vietnam National University of Forestry - Southern Campus; phanvantuandc@gmail.com; \\ ${ }^{4}$ Ho Chi Minh City Institute of Resources Geography, VAST; dmon@hcmig.vast.vn
}

\begin{abstract}
The purpose of this study was to examine the pattern of annual drought variation using the standardized vegetation health index (SVHI) in the central highlands, Vietnam. The time-series imagery of daily MODIS products during the 2001-2020 period were used to compute land surface temperature and normalized difference vegetation index that are two primary parameters of the applied drought index. Besides, the standardized precipitation index (SPI), derived from 5 meteorological stations, was applied to validate the SVHI. Furthermore, the spatial regression approach was used to analyze the spatiotemporal variation of annual drought intensity in the study area. The results showed that the correlation coefficient between SVHI and SPI upon 5 stations was found out at average level above with the significance of 95\% ( $r>0,5, \mathrm{p}<0,05)$. Additionally, the severe drought category seriously influenced in 2005 and 2006 and these years were concurrent with El Niño event. Moreover, an increasing trend in drought patterns focused on agricultural land, while a decreasing trend was explored at forest land upon whole provinces. The results from this study enables providing a useful reference to local governments for proposing strategies of reducing drought risk and forest protection.
\end{abstract}

Keywords: SVHI; VHI; VCI; TCI; MODIS; OLS. 